\title{
UNA VISIÓN CRÍTICA DEL DESEMPEÑO DE LA ECONOMÍA BRASILEÑA EN EL PROCESO DE GLOBALIZACIÓN (1991-2006)*
}

\author{
A CRITIC VIEW OF THE PERFORMANCE OF THE BRAZILEAN \\ ECONOMY IN THE GLOBALIZATION PROCESS' (1991-2006)
}

\author{
Sergio A. Berumen** \\ Milton Silva Guterres da Gama***
}

RESUMEN

Los últimos 15 años han implicado la necesidad de ejecutar grandes cambios en la política económica de Brasil. Como medida para revertir la trayectoria de una creciente inflación y el lento crecimiento económico que prevaleció a lo largo de la década de los ochenta, en los noventa los gobiernos sucesivos adoptaron una política fundada en el ajuste fiscal, las privatizaciones, la desregulación y, en particular, la liberalización comercial. No obstante, los resultados globales logrados por Brasil en los últimos quince años son ambivalentes. Por un lado, el país logró ser internacionalmente más competitivo y, particularmente, ser considerado como una potencia emergente. Pero, por otra parte, los datos aquí mostrados evidencian que el crecimiento económico registrado no impactó lo suficientemente en el desarrollo económico que con urgencia necesitaba este país.

PALABRAS CLAVE: BRASIL * ECONOMÍA * GLOBALIZACIÓN

Se agradecen los valiosos comentarios y sugerencias de Alicia Kaufmann Birch (CEPAL, Santiago de Chile), Silvina Calvo Pelegrini (Universidad de Buenos Aires) y Renato Baumann (CEPAL, Brasilia). Una versión preliminar de este trabajo fue presentada en el curso Brasil, Historia y Cultura, auspiciado por la Facultad de Geografía e Historia de la Universidad Complutense de Madrid, el 6 de noviembre del 2006.

\footnotetext{
** Instituto Politécnico Nacional, México. lee_berumen@racmyp.es

*** Universidad do Rio Grande, Brasil. j713881@yahoo.com.br
} 


\section{ABSTRACT}

The last 15 years implied the need to carry out major changes in the Brazilian economic policy. As a measure to stop the upgrowing inflation and to promote the slow economic growth and development that prevailed through the decade of the eighties, in the nineties the governments decided to adopt a policy based in the fiscal settlement, privatizations, regulation and, particularly, commercial liberalization. Notwithstanding, global results obtained in Brazil in the last 15 years are ambivalent. In one side, the country became more competitive, internationally speaking, and, particularly, to be considered an emerging power.

KEY WORDS: BRAZIL * ECONOMY * GLOBALIZATION

\section{INTRODUCCIÓN}

En los últimos 15 años ha tenido lugar una inmersión de los países latinoamericanos en la globalización de la economía, los cuales han sido escenario de intensos cambios, tanto de orden político como económico. En el plano político, en este tiempo se sentaron las bases para que los países se sumaran a la normalidad democrática. Pero lejos de haber disenso, en la inmensa mayoría de los países del área los diversos gobiernos adoptaron las políticas derivadas del denominado Consenso de Washington, las cuales se orientaron a una acelerada apertura comercial, liberalización de los mercados financieros, reducción del gasto público, a una frenética búsqueda de inversión extranjera directa y a la privatización o liquidación de empresas públicas.

Brasil no fue la excepción. A lo largo de los últimos 15 años la economía brasileña se aferró al ideal de formar parte de la globalización económica como una potencia emergente. Al igual que China, India, Sudáfrica y México, Brasil emprendió una serie de medidas orientadas a hacer prevalecer un ambiente más competitivo y liberal, $y$ de olvidar los viejos tiempos del Sistema de Sustitución de Importaciones (SSI).

En el presente artículo se hace un recorrido por la senda que transitó este país en el afán de participar en la globalización con voz propia. El contenido está estructurado en tres partes. En la primera se hace una revisión del proceso que conllevó a que Brasil abrazase la política neoliberal en los últimos 15 años; el interés es el de mostrar los avatares y las oportunidades económicas a las que se enfrentó este país en su búsqueda por lograr insertarse en la globalización. La segunda se centra en el crecimiento sectorial y en el ejercicio de comercio, orientado a alcanzar una balanza comercial favorable. Y finalmente, en el último punto se analiza el papel que desempeñó Brasil en el seno de los miembros del MERCosur; aquí se constatará la supremacía de su economía sobre la de los otros miembros, $y$ la importancia que tiene la solidez de su economía para el buen funcionamiento de esta asociación de países.

Hoy en día, Brasil se disputa el título de Primera Economía Latinoamericana. Resulta evidente que este país cuenta con acervos de capital importantes, se trata de una nación joven que está densamente poblada, que cuenta con recursos humanos y naturales de suma importancia, es un país con fuerte personalidad que es fácilmente distinguible en el escenario internacional $y$, en general, ha habido una tendencia a generar una cultura cada vez más generalizada de aversión al riesgo. Sin embargo, en contraposición, Brasil presenta serios déficits en cuanto al respeto a los derechos humanos, hay una abismal repartición del ingreso, el ambiente político es de crispación, es plenamente deficitaria en Investigación y Desarrollo (I+D) y se trata de una economía que en el pasado contrajo deudas que ahora resultan un lastre para su pleno crecimiento.

\section{LA INMERSIÓN DE BRASIL EN LA POLÍTICA NEOLIBERAL}

Los primeros pasos en pro de una liberalización económica en América Latina se llevaron 
a cabo en Argentina, Chile y Uruguay en la década de los setenta. Pero, debido a las crisis que conllevaron a la insolvencia para el pago del servicio de la deuda (entre 1982 y 1985), se paralizaron varias de las reformas incluidas en los programas de liberalización diseñadas con anterioridad. Para Ocampo (2001), en algunos casos se llegó incluso a la instauración de controles a la apertura de las cuentas de capitales, aumento de tarifas arancelarias, la imposición de barreras no arancelarias (v.g. los contingentes) y la intervención ( $y$ en algunos casos se llegó hasta la nacionalización) de los bancos privados con riesgo de caer en insolvencia. A partir de mediados de los ochenta el escenario cambió sustancialmente. En la Gráfico 1 se aprecia que a partir de 1985 en América Latina las reformas económicas se llevaron a cabo en un ambiente de acelerada apertura comercial, liberalización de los mercados financieros, en la cuenta de capitales $y$ en la privatización de empresas públicas (CEPAL, 2004).

Durante la década de los noventa la mayoría de los países latinoamericanos y del Caribe adoptaron las reformas del denominado Consenso de Washington en una tentativa por controlar la inflación y retomar la senda del crecimiento económico. Brasil no fue la excepción. En 1994 el Plan Real hizo posible la reducción de la inflación; este plan de ajuste, junto con las reformas económicas liberalizadoras y la captación de inversión extranjera directa, a la postre fueron elementos que permitieron crear una expectativa de crecimiento sostenible en el largo plazo (Gremaud et al., 2005) ${ }^{1}$.

Previo a la adopción de las reformas estructurales, en Brasil prevalecieron condiciones de deterioro de la economía, tales

1 Añadidamente a lo aquí señalado, el Plan Rea (Plano Real) limitó radicalmente el gasto del gobierno, introdujo una nueva moneda (lo cual implicó una devaluación encubierta) e impuso severas reformas de tipo fiscal. En el apartado de las privatizaciones, el gobierno vendió empresas financieras, de manufactura, del sector minero y la mayoría de las empresas del acero (una de las más representativas empresas privatizadas fue la Companhia Vale do Rio Dôce-CVRD). Asimismo, el gobierno vendió una parte minoritaria de la empresa Petrobrás, con lo cual, fue el modesto banderazo de salida (si bien, muy representativo) para que los capitales privados participaran en la industria petrolera brasileña.

\section{GRÁFICO 1}

\section{ÍNDICES DE LAS REFORMAS ECONÓMICAS EN AMÉRICA LATINA (1970-2000)}

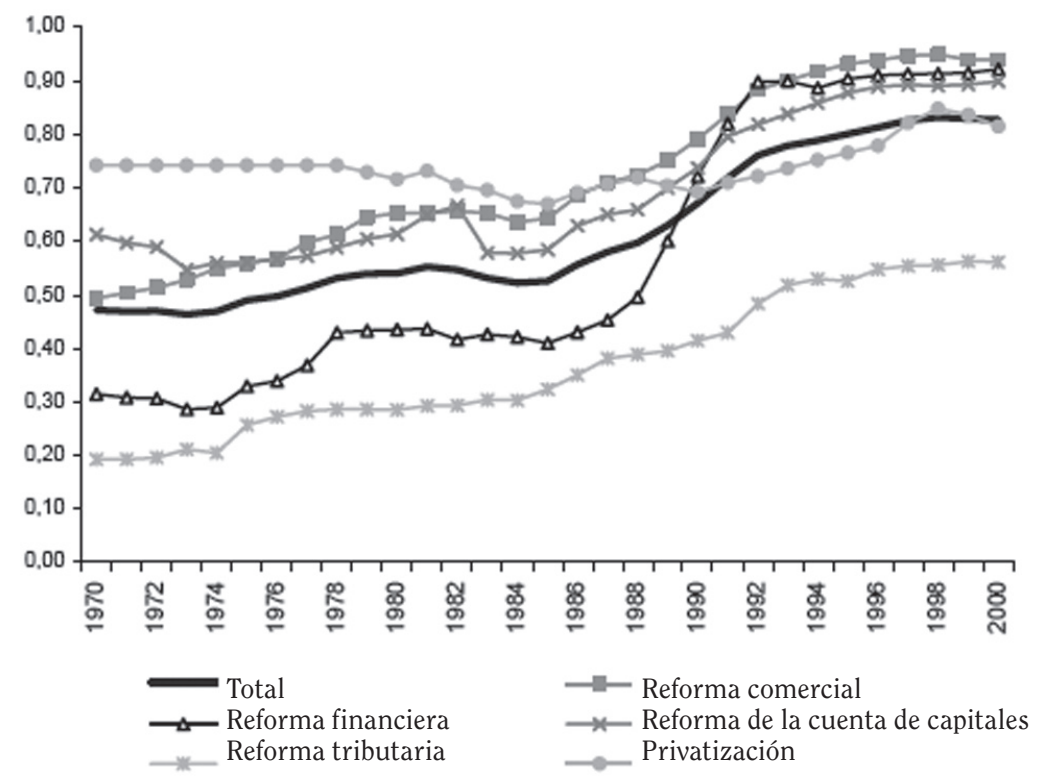

Fuente: CEPAL, 2004: 63. 
como: i) una acelerada inflación; ii) disminución de las tasas de inversión; iii) tasas muy pobres $y$ declinantes de crecimiento económico; iv) grandes déficits fiscales; v) contracción de la intermediación financiera; vi) bajas tasas de generación de empleo; $y$ vii) grandes desigualdades económicas en la repartición del ingreso, entre otras. Anterior a 1990 los gobiernos habían basado su estrategia económica en la preeminencia del Sistema de Sustitución de Importaciones (SSI), si bien con matices específicos a los señalados por la CEPAL. El SSI provocó una persistente ineficiencia productiva y la ineficacia de la administración federal para hacer frente a los problemas de pobreza. Como lo señala Gomes Nuno (2003), como medida para revertir la trayectoria de una creciente inflación y el lento crecimiento económico, los gobiernos sucesivos adoptaron una política fundada en el ajuste fiscal, las privatizaciones, la desregulación y, en particular, la liberalización comercial. Esta última se puso en marcha en un período relativamente corto de tiempo (1990-1993) y fue el instrumento de política clave dirigido a la estabilización de precios.

Pero las reformas estructurales no condujeron la economía hacia un desempeño macroeconómico satisfactorio (cuando menos no con la rapidez deseada). En la primera mitad de la década de los noventa el gobierno contaba en sus haberes con un cierto excedente en la cuenta corriente $y$ detentaba amplias reservas de divisas. Empero, en la segunda mitad de los noventa este escenario general se revirtió, registrándose un rápido deterioro de algunas de las variables macroeconómicas. El mérito de los tecnócratas brasileños fue que para finales de 1997 consiguieron reducir considerablemente las tasas de inflación: la tasa de inflación anual pasó del nivel de $2.000 \%$ registrado en 1994, a $66 \%$ en 1995, y triunfalmente alcanzó el nivel de un dígito (6,9\%) en 1997 (Banco Central do Brasil, 2004: 85-97).

Un conjunto de factores contribuyó al mencionado deterioro económico. Primero, el aumento de los déficits públicos fue una respuesta al incremento del número de empleados públicos jubilados, un aumento real significativo del valor del salario mínimo (con los consiguientes incrementos de las pensiones y los beneficios de seguridad social) y un deterioro de la situación fiscal de los gobiernos regionales. Segundo, el Banco Central adoptó una política de restricción monetaria para evitar una burbuja de consumo tras la rápida caída de la inflación registrada en 1995. Tercero, con una tasa de cambio sobrevaluada y bajas tarifas, se produjo un rápido deterioro de la balanza comercial, la cual registró déficits en toda la segunda mitad de la década de los noventa y los primeros cuatro años de la actual.

La sobrevaluación de la tasa de cambio y el deterioro de la balanza comercial que caracterizaron a la mayor parte de los noventa, contribuyeron a empeorar el déficit de la cuenta corriente, mientras que recién en 1999 se cambió la política de tasa de cambio al introducir un régimen de tasa de cambio flotante. El déficit de la cuenta corriente, que promedió 0,3\% del Producto Interno Bruto (PIB) en 1994, alcanzó 4,5\% en 1998, y 6,3\% en el 2003. Otros factores adicionales que contribuyeron a este deterioro fueron la crisis de tasa de cambio en 1998 y el mal desempeño de la cuenta de servicios, debido principalmente a los incrementos registrados en los pagos de intereses y remesas de ganancias al exterior (OECD, 2004: 86-92).

Estos factores fueron consecuencia directa de las elevadas tasas de interés reales externas pagadas por Brasil a los acreedores internacionales de los bonos de la deuda brasileña, el incremento de la deuda externa $y$ de inversiones extranjeras directas (que en el 2000 representaron alrededor de 9,7\% del PIB y en el 2004 , el 10,6\%) comparadas con la insignificante participación de $0,2 \%$ en 1990 . En los años comprendidos entre 1998 y 2004 el escenario que prevalecía presentaba dos grandes frentes: i) el insuficiente desempeño económico en términos de tasas de crecimiento económico (tasas menores al 1,5\% anual); $y$ ii) la persistente inflación (con tasas superiores al 6\% anual). La decisión adoptada por el gobierno se orientó a desacelerar la actividad económica para ganar control sobre la inflación. Las tasas de crecimiento del PIB, que promediaron 2,9\% anual en la década de los ochenta, se redujeron a un promedio anual de $1,7 \%$ en los noventa y a 1,5\% en 2004 (Banco Central do Brasil, 2004: 103-109).

Como se ha dicho anteriormente, en los últimos quince años el gobierno priorizó la 
implementación de medidas en pro de la liberalización comercial, el control de la inflación y la imposición de una férrea disciplina fiscal. A medida que el gobierno promovió las reformas económicas, tanto el sector privado (el cual creció en un 13,7\%) como el sector público (que creció en un $6,2 \%$ ) se convirtieron en los detonadores principales de crecimiento. La contribución del sector externo, sin embargo, fue negativa (este decreció en un -3,5\%). En la segunda mitad de la década de los noventa las exportaciones mantuvieron su comportamiento $y$, por tanto, crecieron menos que las importaciones, lo cual contribuyó a generar un impacto negativo en el sector externo con respecto al crecimiento del PIB. En ese entonces se registraron las mismas tendencias que prevalecieron en el período de post-liberalización (que comprendió de 1995 a 1998), aunque con menor intensidad (-0,8\%). El principal impacto positivo provino del sector privado. En consecuencia, la participación del total de exportaciones y la inversión en la demanda agregada se redujo después de 1990, mientras que aumentó la participación respectiva del gasto del gobierno y del consumo privado (OECD, 2004: 116-124).

En la década de los noventa, Brasil tuvo a tres grandes protagonistas: Fernando Collor de Mello (1990-1992), Itamar Franco (19921994) y Fernando Enrique Cardoso (1994-2002) (Sforzi, 2003: 41-57). Si bien cada uno desempeñó un rol diferenciado, el común denominador fue que los tres gobiernos fueron declaradamente de corte neoliberal; sin embargo, el balance general de estos doce años, fue que la economía brasileña estuvo lejos de alcanzar las tasas de crecimiento económico que demandaba el país, $y$ más aún, de reducir la pobreza. Ante esta situación, en el 2003 asumió el poder Luiz Inácio "Lula" da Silva, quien era el líder indiscutible del Partido de los Trabajadores (PT), enarbolando un discurso de profundo talante progresista. Pero sorpresivamente, como lo señala Palermo (2006: 24-36), desde el inicio de su mandato Lula se decantó por implementar una política macroeconómica más acorde con los postulados neoliberales, tales como disciplina fiscal y monetaria, y la aplicación de reformas estructurales (en especial la de tipo tributario), mismas que con anterioridad fueron severamente criticadas por él mismo como dirigente del PT y por diversos segmentos de la sociedad contrarios al pensamiento económico monetarista.

La constitución de Lula como presidente de Brasil en enero de 2003, creó una expectativa de cambio en la orientación de la política económica; muestra de ello fue que en diversas ocasiones Lula prometió que su país se desmarcaría (cuando menos parcialmente) de los dictados del sistema financiero internacional, pues argumentaba que el Efecto Samba (1999), si algo había enseñado, fue que no era conveniente que la buena marcha de la economía reposara en manos de los mercados financieros. Estaba decidido a que las implicaciones derivadas del Efecto Samba no serían olvidadas y, por lo tanto, no se caería en los errores en lo que se incurrió en el pasado. La solución de Lula en este renglón consistía en desconfiar del exterior y, por tanto, sustentar el crecimiento económico en las potencialidades internas. Incluso, en la celebración de la Cumbre de Río ${ }^{2}$, Lula fue un entusiasta promotor de una globalización alternativa, en una opción divergente al actual modelo imperante.

Cuando fue electo, un alto porcentaje de la población sembró en él sus esperanzas pues estaba convencida de que tendría la clave para hacer que Brasil creciera, pero con una mayor equidad en la distribución de la riqueza. Sin embargo, desde su llegada al gobierno, Lula evidenció que en su faceta como Presidente quedarían relegadas sus posturas más reformistas. Desde la constitución de su gabinete de gobierno envió una clara señal de que muchas de sus viejas promesas no podrían ser cumplidas. Los opositores a Lula denunciaron que las principales carteras ministeriales fueron confiadas a representantes destacados de los principales

2 La denominada Cumbre de Río, en realidad se llamó Conferencia sobre el Medio Ambiente y el Desarrollo, y fue convocada por las Naciones Unidas, a celebrarse en la ciudad de Río de Janeiro del 3 al 14 de junio de 1992. El interés de esta Cumbre fue el de reunir a los más altos representantes de la política (asistieron 117 jefes de Estado y de Gobierno y estuvieron representadas 178 naciones) $y$ de los sectores productivos para que asumieran un compromiso, orientado a alcanzar mejores tasas de desarrollo económico para los individuos y el uso más mesurado de los recursos medioambientales a nivel planetario, en particular, de los recursos no renovables. 
grupos industriales del país, lo que les hacía presumir que en buena medida estos verían primeramente por sus intereses de grupo $y$ después por los del país en general (Moreira de la Hoz, 2006: 48-50). Sin duda, el puesto más controvertido fue el de Enrique Meirelles (quien fuera presidente del Banco Central y connotado banquero del Bank of Boston). Con esto Lula pretendió enviar una inequívoca señal a los mercados: la continuidad en la aplicación de la política de orden neoliberal.

A lo largo de su primer mandato, no sólo hubo continuidad en el enfoque de aplicar la política económica, sino que, en algunos casos se agudizó, tal como fue el superávit primario, control de la inflación, disciplina fiscal y la urgencia de las reformas del sistema de pensiones y tributario. Tras este primer período de gobierno, Lula insistió en que lo primero era llevar a buen término las inconclusas reformas monetaria y fiscal, para que ello posibilitara el control de las altas tasas de interés que aún imperan, y que son necesarias para mantener la inflación y la deuda pública bajo relativo control.

En los primeros cuatro años de gobierno de Lula, los esfuerzos se centraron en atender los problemas de corto plazo, tales como la reducción del riesgo en el país que permitiera captar una mayor cantidad de inversión extranjera directa, control inflacionario y el fortalecimiento del mercado financiero. Dias Leite (2006) y Giambiagi et ál. (2007) coinciden en señalar que, bajo este enfoque, hasta diciembre de 2005 Brasil captó 11,5 billones de dólares estadounidenses en el mercado accionario, debido a la alta rentabilidad que ha ofrecido la Bolsa de Valores (el riesgo, sin embargo, es la posibilidad de que se esté formando una burbuja bursátil que, tarde o temprano, termine por estallar). Por otro lado, hasta 2005 fue claro el cuadro de recesión económica; el escaso crecimiento se tradujo en una reducción de la renta en términos reales y en el consumo de bienes.

$\mathrm{Al}$ inicio de la gestión de gobierno se planeó el aumento de la meta del superávit fiscal de $3,7 \%$ a $4,25 \%$ del PIB, a costa de la contracción de los programas sociales, y se había abstenido de bajar la tasa básica de interés (Moreira de la Hoz, 2006: 52-60). Aunque estas medidas fueron acogidas con entusiasmo por el sector financiero, han significado una restricción de liquidez en la economía; en particular, contribuyeron a que entre abril y junio de 2003, por ejemplo, hubiese una contracción económica de $1,6 \%$ respecto a los tres meses anteriores, que a su vez habían experimentado una tasa negativa de $0,6 \%$. Al mismo tiempo, el desempleo abierto en las zonas metropolitanas en el segundo trimestre de 2003 alcanzó $12,8 \%$, y del 12,4\% en el último trimestre de 2006, el índice más alto en la historia reciente, $y$ los salarios reales de los trabajadores continuaron cayendo (Banco Central do Brasil, 2007: 32-41).

En virtud de lo anteriormente señalado, particular atención merece la relación entre Lula $y$ los diversos movimientos sociales, fundamentalmente el Movimiento de los Sin Tierra (MST). Los partidarios de la izquierda tuvieron que conciliar sus ambigüedades (estas sólo parcialmente superadas en el ocaso de la vida del Partido Comunista de Brasil-PCB) en relación con el pleno ejercicio de la democracia como único medio de reforma y perfeccionamiento de la sociedad brasileña. Si para el PT alcanzar la Presidencia constituyó el momento álgido en su evolución de partido social a partido de la política, para el MST también parece haber llegado la hora de caminar hacia su propia institucionalización (Felgueres Freire, 2005: 75-93).

En este segundo mandato de Lula al frente del gobierno brasileño, habrá que ver si el MST seguirá exigiendo a su líder una mayor contundencia en sus acciones, en pro de alcanzar sus viejos reclamos de igualdad de oportunidades y reparto de la tierra. Hasta ahora, Lula ha preferido la moderación, si bien se ha mantenido firme en la intención de alcanzar sus propósitos sociales originales.

\section{CRECIMIENTO SECTORIAL Y COMERCIO EXTERIOR}

La agrupación de países en escenarios regionales de carácter comercial se ha tornado en una realidad cotidiana muy común en todo el mundo, y América Latina no ha sido la excepción. Pero hace relativamente poco tiempo los países latinoamericanos se encontraban regidos bajo el patrón común de la aplicación de las 
políticas emanadas del Sistema de Sustitución de Importaciones (SSI). Hoy en día la apertura comercial se presenta como la única alternativa por la que han optado los diversos gobiernos del continente.

$\mathrm{El}$ antecedente del MERCOSUR tiene lugar en 1979, cuando Uruguay y Brasil firmaron el Protocolo de Expansión Comercial (PEC); este pacto a la postre también indirectamente incluyó a Argentina por medio del Convenio ArgentinoUruguayo de Cooperación Económica (CAUCE). Entre 1984 y 1989 Argentina y Brasil suscribieron veinticuatro protocolos bilaterales, $y$ en 1985, en el marco de un encuentro de cooperación bilateral, se dio vida a la Declaración de Foz de Iguazú, en la que se creó una Comisión Mixta de Alto Nivel para la integración comercial entre Argentina y Brasil (Petriccioli, 2006: 46-110).

Más recientemente, en 1990 Argentina y Brasil suscribieron un Acuerdo de Complementación Económica que tuvo por objeto reactivar e incentivar los acuerdos ya existentes. Y meses después, Argentina y Brasil abrieron la posibilidad para que tanto Uruguay como Paraguay se incorporaran al proceso de integración. Fue hasta entonces cuando definitivamente surgió la intención de crear un marco económico común en el que estuvieran comprendidos los cuatro países. El 26 de marzo de 1991 tuvo lugar la firma del Tratado de Asunción entre Brasil, Argentina, Uruguay y Paraguay; este acuerdo entró en vigor el 28 de noviembre de 1991. Para los efectos que el Tratado de Asunción no contemplaba (o lo hacía de forma parcial) los cuatro países miembros suscribieron el Protocolo de Ouro Preto el 17 de diciembre de 1994. Finalmente, el 1 de enero de 1995 entró en vigor la Unión Aduanera en el MERCOSUR (Idem: 123).

Durante la década de los noventa los miembros del MERCOSUR adoptaron las denominadas reformas del Consenso de Washington en una tentativa por controlar la inflación y retomar la senda del crecimiento económico. Brasil se decantó por una política restrictiva del gasto, disciplina fiscal, apertura comercial y financiera, desregulación, privatización de empresas públicas y la captación de inversión extranjera directa; con estas estrategias se pretendía crear una expectativa de crecimiento a largo plazo. En las siguientes gráficas se expondrá el comportamiento que mostró la economía de Brasil en el comercio de los países del MERCOSUR en la década de los noventa (se destacará principalmente su posición competitiva). En el Gráfico 2 se muestra la posición de Brasil como exportador en el MERCOSUR.
1. Argentina

2. Brasil
3. Uruguay

4. Paraguay

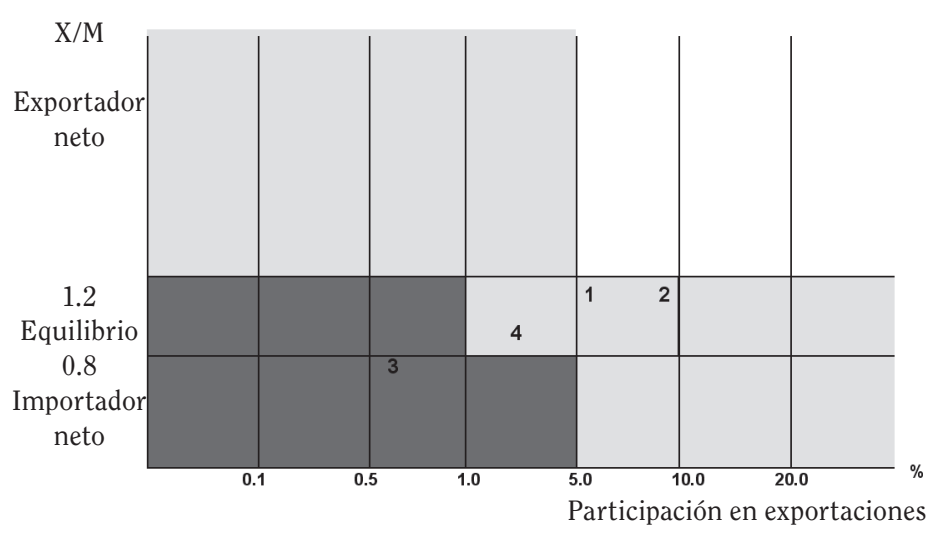

Fuente: Elaboración propia con base a Tartakowski y Chirulnicoff (2006: 561-570). 
En el eje vertical se mide la balanza comercial de mercancías como la razón de las exportaciones a las importaciones, mientras que el eje horizontal mide la participación de las exportaciones de cada país en el comercio internacional. Para efectos de este artículo, se parte de la concepción de que la competitividad es: i) la capacidad de lograr que las exportaciones alcancen una participación de mercado en el comercio mundial tal que permita lograr una balanza comercial equilibrada o con un pequeño superávit en condiciones de economía abierta; $y$ ii) que esto permita lograr altos estándares de bienestar material para la población.

En los últimos 15 años Brasil fue el principal exportador dentro de los países del MERCOSUR, seguido relativamente de cerca de la Argentina. Este gráfico demuestra que Brasil tuvo niveles de competitividad muy semejantes a los de Canadá, y Argentina a los de Australia. Por otro lado, la competitividad de Brasil y de la Argentina fue semejante a la de países desarrollados y que se rigen bajo dos esquemas característicos: i) cuyas exportaciones son altamente dependientes de recursos naturales, como es el caso de Noruega (este país, de sólo 4 millones de habitantes, ocupa el tercer lugar como exportador de petróleo); y ii) cuyas exportaciones están dominadas por operaciones de ensamblado, como es el caso de Irlanda (este país es el líder en el ensamblaje de ordenadores). Lo que refleja este ejercicio es que Brasil fue el líder indiscutible del área. En el Gráfico 3 se muestra la tendencia como exportador que mostró Brasil en el seno del MERCOSUR en los últimos 15 años.

La asimilación de las políticas derivadas del Consenso de Washington por Brasil, le permitieron incrementar su participación de mercado como exportador, si bien fue insuficiente su capacidad para mejorar la condición de su balanza comercial. Ello probablemente obedeció a las condiciones heredadas del periodo previo, caracterizado por un proceso de desintegración de los incipientes encadenamientos productivos. Finalmente, en el Gráfico 4 se muestra la tendencia como importador de los países del MERCOSUR.

\section{GRÁFICO 3}

TENDENCIA DE BRASIL COMO EXPORTADOR

EN EL MERCOSUR
1. Argentina
3. Uruguay
2. Brasil
4. Paraguay

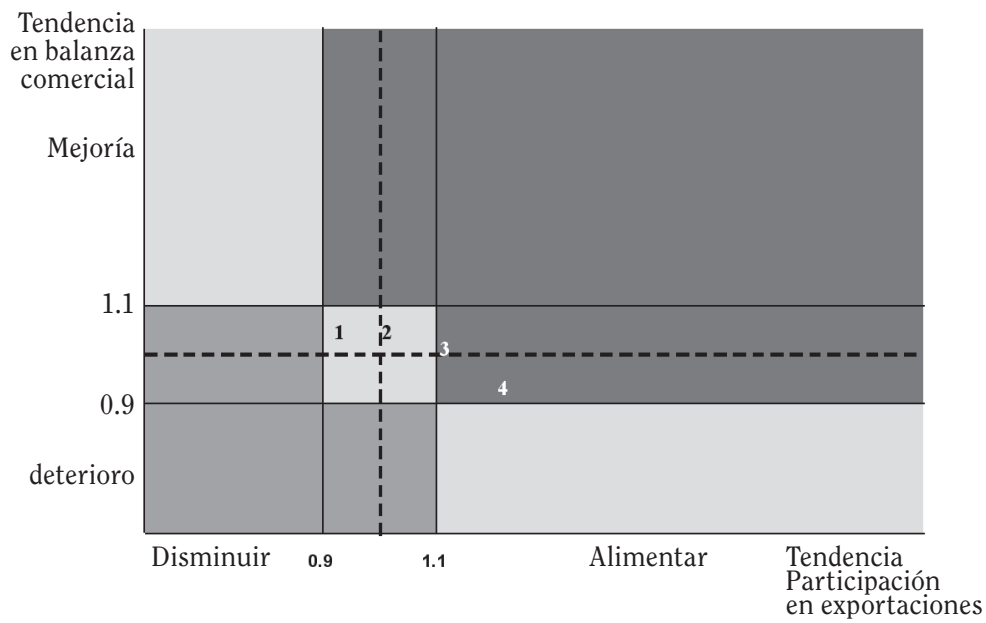

Fuente: Elaboración propia con base a Tartakowski y Chirulnicoff (2006: 571-579). 


\section{GRÁFICO 4}

TENDENCIA DE BRASIL COMO IMPORTADOR

EN EL MERCOSUR
1. Argentina
3. Uruguay
2. Brasil
4. Paraguay

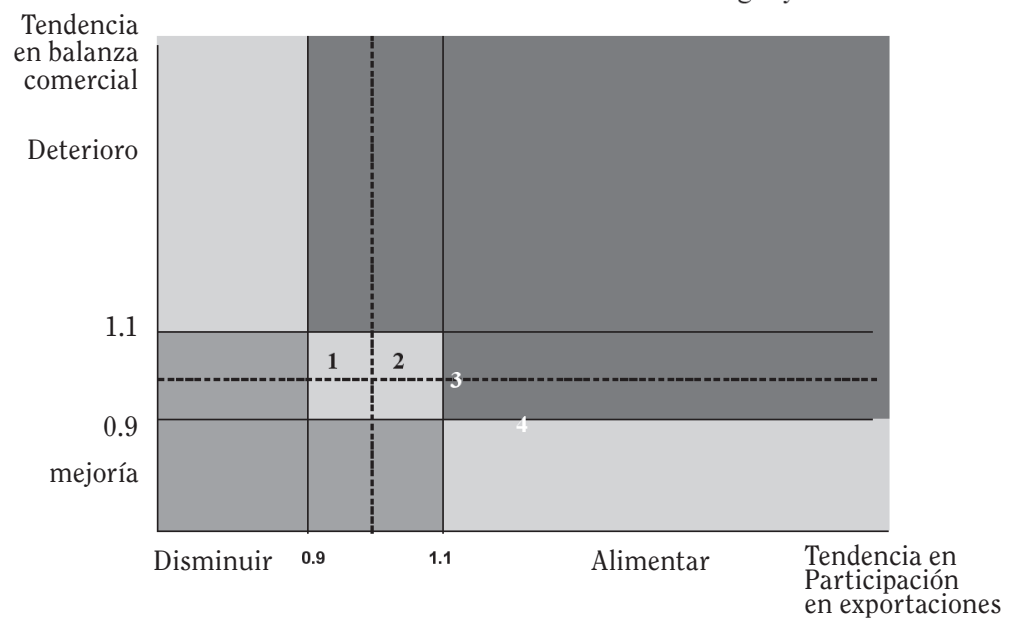

Fuente: Elaboración propia con base a Tartakowski y Chirulnicoff (2006: 587-603).

En cuanto a la tendencia como importador Brasil manifestó una tendencia al equilibrio entre las exportaciones y las importaciones.

En el largo período considerado de 1975 a 2006, la demanda interna fue siempre el determinante principal del crecimiento del PIB brasileño (ver Cuadro 1). El SSI contribuyó positivamente durante el período de los planes económicos heterodoxos (entre 1984 y 1987) en la medida en que las importaciones fueron restringidas para evitar déficits comerciales y generar divisas para enfrentar el pago del servicio de la deuda externa (Barros y Corseuil, 2007, pp. 82-116). Mientras la inflación se acercaba a niveles

\section{CUADRO 1}

\section{DESCOMPOSICIÓN DEL CRECIMIENTO DEL PIB-PERÍODOS SELECCIONADOS}

\begin{tabular}{|c|c|c|c|c|c|c|}
\hline & $1975-80$ & 1981-83 & 1984-87 & 1988-94 & 1995-99 & $2000-06$ \\
\hline \multicolumn{7}{|c|}{ NÚMEROS ABSOLUTOS } \\
\hline PIB & 1,30 & $-0,14$ & 0,97 & $-0,11$ & 0,42 & 0,40 \\
\hline Demanda Interna & 1,14 & $-0,24$ & 0,97 & 0,1 & 0,55 & 0,43 \\
\hline Sustitución de Importaciones & 0,01 & 0,03 & 0,09 & $-0,07$ & $-0,24$ & $-0,04$ \\
\hline Exportaciones & 0,15 & 0,07 & $-0,09$ & $-0,15$ & 0,11 & 0,01 \\
\hline \multicolumn{7}{|c|}{ CAMBIO PORCENTUAL } \\
\hline PIB & 100 & 100 & 100 & 100 & 100 & 100 \\
\hline Demanda Interna & 87,6 & 171,1 & 100,1 & $-111,4$ & 132,3 & 106,9 \\
\hline Sustitución de Importaciones & 0,6 & $-22,3$ & 9,2 & 66,4 & $-58,3$ & $-9,4$ \\
\hline Exportaciones & 11,8 & $-48,8$ & $-9,3$ & 145,0 & 26,0 & 2,5 \\
\hline
\end{tabular}

Fuente: Elaboración propia con base en Barros y Corseuil (2007: 82-116). 
hiperinflacionarios, el producto total decreció como resultado de exportaciones decrecientes e importaciones crecientes.

En la primera mitad de la década de los noventa la principal fuente de crecimiento económico fue la demanda interna, seguida por un crecimiento de las exportaciones y un proceso de importaciones rápidamente crecientes, dado que las barreras y tarifas comerciales habían caído y la tasa de cambio se había sobrevaluado considerablemente. Entre 1995 y 1998, el crecimiento acumulado del PIB era aproximadamente el mismo en magnitud que el registrado para la primera parte de la década, pero la principal fuente de crecimiento fue la demanda interna, dado que las exportaciones perdieron dinamismo $y$ las importaciones crecieron, si bien ligeramente.

Desde 1981 a 1994, la balanza comercial fue siempre favorable a Brasil, pero antes $y$ después de esos años la cuenta comercial fue altamente negativa. El excedente registrado desde 1981 en adelante sobrevino después de un fuerte ajuste económico tras la crisis del petróleo en el campo internacional y de una significativa devaluación de la tasa de cambio. En un período muy corto, las importaciones subieron de 20500 millones de dólares en 1992 a 50000 millones de dólares en 1995. Mientras tanto, el total de exportaciones aumentó de 35700 millones de dólares en 1992 a 46500 millones de dólares en 1995 (Ash, 2005: 14-29). Los déficits desde 1995 en adelante fueron el resultado de la combinación de liberalización comercial, la utilización de las importaciones como instrumento para disciplinar la formación de precios internos y la sobrevaluación de la tasa de cambio. De este modo, el régimen más liberal de comercio y la sobrevaluación de la tasa de cambio fueron parte de una reforma económica más amplia que buscaba principalmente detener la inflación al costo de aumentar los déficits comerciales.

Aunque la apertura económica mejoró el desempeño tanto de las importaciones como de las exportaciones, la tasa de crecimiento de las exportaciones no consiguió emparejar la tasa de crecimiento de las importaciones. La tasa de crecimiento de las exportaciones alcanzó $4,39 \%$ en los años ochenta, pero se redujo a un promedio anual de 1,34\% en los noventa. La participación de los bienes industriales en las exportaciones totales subió de $45 \%$ en 1980 a $61 \%$ en el 2000 , mientras que la participación de los bienes primarios descendió de $43 \%$ a $23 \%$ en el mismo período. Entre tanto, los términos del intercambio se hicieron desfavorables, lo que demandó mayores exportaciones para enfrentar la masiva cantidad de las importaciones (Banco Central do Brasil, 2002: 45-63).

La penetración de las importaciones industriales experimentó un aumento constante después de 1990. Desde 1990 hasta el 2006, la penetración de las importaciones se duplicó: creció de 5,5\% en 1990 a 13,4\% en el 2006. Es menester enfatizar que no se pueden encontrar pautas claras a la penetración de las importaciones para las industrias tradicionales y modernas, como podría esperarse. Una posible explicación de esto es que Brasil enfrentó más competencia después de la liberalización comercial, tanto de países desarrollados como de otros en desarrollo que habían adoptado reformas comerciales al mismo tiempo, como China, India, Indonesia, Malasia y Sudáfrica, entre otros (Arbache, 2005: 347-392). La necesidad de aumentar las exportaciones para financiar importaciones después de la apertura comercial, afectó a países de ingresos medios como el Brasil.

Los coeficientes de intensidad de exportaciones mostraron una leve tendencia negativa en el tiempo, $y$ el período de apertura comercial no parece haber afectado las exportaciones debido a que no hubo un cambio aparente en la década de los noventa. Mientras que la penetración de las importaciones aumentó, el coeficiente de intensidad de las exportaciones permaneció relativamente estable. Ambas tendencias evidencian que las empresas brasileñas en ese tiempo no eran competitivas internacionalmente. Los costos unitarios de mano de obra muestran una alta volatilidad, la cual se explica principalmente por cambios de la tasa de cambio real $y$, en menor medida, por variaciones en los salarios reales. En la década de los ochenta se registró una tendencia al alza; en los noventa, en cambio, ocurrió justo lo contrario. Dos efectos concurrentes afectaron potencialmente a los costos de mano de obra de la última década. Por un lado, el Real se sobrevaluó en relación al dólar estadounidense, lo que provocó un aumento del costo unitario de mano 
de obra. Por otro lado, la productividad laboral creció rápidamente, lo que condujo a una reducción del costo laboral. En general, parece que el último efecto dominó al primero, lo que permitió que la economía brasileña se hiciera más competitiva.

La mayor apertura registrada en la década de los noventa permitió que la economía de este país importase más bienes de capital y tecnología (lo que implicó un desplazamiento de la función de producción hacia arriba). Una mayor competencia disciplinó la formación de precios e hizo que las empresas produjeran con mejor calidad $y$ a menor precio. Empero, el crecimiento de las exportaciones tuvo un impacto limitado sobre la generación de empleo, mientras que el crecimiento de las importaciones y la introducción de nuevas tecnologías en los procesos de producción asistió a la destrucción neta de alrededor de 5,4 millones de empleos (Maia, 2005: 452-461). Los sectores que se beneficiaron del crecimiento de las exportaciones en los últimos 15 años fueron los de mayor intensidad de capital (y justo eran los que utilizaban mano de obra cualificada). De este modo, los aumentos registrados en la informalidad y los niveles promedio de desempleo afectaron mayoritariamente a los trabajadores menos cualificados. Sin embargo, como bien lo señala Green (2004: 1923-1939), la creciente exposición al comercio mundial no promovió mejoras ni en los indicadores de desigualdad.

\section{CONCLUSIONES}

Los últimos 15 años significaron la necesidad de ejecutar grandes cambios en la política económica de Brasil. Los gobernantes de este país optaron por adaptarse a las disposiciones decretadas en el seno del Consenso de Washington. Para tal efecto, la economía de este país fue sometida a sendos programas de ajuste (el más destacado de ellos fue el Plan Real). Como medida para revertir la trayectoria de una creciente inflación y el lento crecimiento económico que prevaleció a lo largo de la década de los ochenta, en los noventa y lo que va de la presente, los gobiernos sucesivos adoptaron una política fundada en el ajuste fiscal, las privatizaciones, la desregulación y, en particular, la liberalización comercial.
En la primera mitad de la década de los noventa el gobierno contaba en sus haberes con un cierto excedente en la cuenta corriente $y$ detentaba amplias reservas de divisas. Pero de 1996 al 2006 este escenario general se revirtió, registrándose un rápido deterioro en algunas de las variables macroeconómicas. En lo referente al papel que desempeñó Brasil en el seno del MERCOSUR, se evidencia que, con diferencia, este país es la economía más potente del área. En la década de los noventa Brasil fue el principal exportador dentro de los países del MERCOSUR. Brasil mostró niveles de competitividad muy semejantes a los de Canadá; su estrategia competitiva se rigió, principalmente, en ser un eficiente exportador de recursos naturales y en operaciones de ensamblado de alta tecnología. Ambos aspectos le permitieron incrementar su participación de mercado como exportador, si bien fue insuficiente su capacidad para mejorar la condición de su balanza comercial.

No obstante, los resultados globales logrados por Brasil en los últimos 15 años son ambivalentes. Por un lado, el país logró ser internacionalmente más competitivo $y$, particularmente, ser considerado como una potencia emergente, prácticamente al mismo nivel que Sudáfrica o India. Pero, por otra parte, los datos aquí mostrados evidencian que el crecimiento económico registrado no impactó lo suficientemente en el desarrollo económico que con urgencia necesitaba este país. La llegada de Lula al poder no ha significado una reconducción en el diseño de la política económica.

\section{REFERENCIAS}

Arbache, John S. "Trade liberalization and labour markets in developing countries: theory and evidence". A. Levy e J.R. Faria (eds.). Economic Growth, Inequality and Migration: National and International Perspectives. Cheltenham, Edward Elgar. 2005: 347-392.

Ash, Timothy. "An econometric analysis on Brazil's economy". Journal of International Political Economy 12. 4, junio-diciembre, 2005: 14-29. 
Banco Central do Brasil. 2001 Anual Report. Brasilia: Banco Central do Brasil, 2002: 45-63.

2003 Anual Report. Brasilia. Banco Central do Brasil, 2007: 32-41.

Relatório de enflaçao. Brasilia. Banco Central do Brasil, 2007: 85-97.

Barros, Rafael y Corseuil, Charles H. "Abertura econômica e distribuição de renda no Brasil", Proceedings of the Workshop on Trade Liberalization and the Labor Market in Brazil, UnB/IPEA. Brasilia. 2007: 82-116.

CEPAL. Desarrollo productivo en economías abiertas. Santiago de Chile: CEPAL, 2004: 63-70.

Dias Leite, Antonio. Economia Brasileira: De onde viemos e onde estamos. Rio de Janeiro: Editorial Campus, 2006.

Felgueres Freire, Mario. Diccionario de organizaciones anti globalizadoras: de Greenpeace al movimiento Zapatista. La Coruña. Ediciones Juan Mangabeira, 2005: 75-93.

Giambiagi, Fabio; Villela, Andre; Barros de Castro, Lavinia et ál. Economia Brasileira Contempoânea. Sao Paolo: Editorial Campus, 2007.

Gomes Nuno, Nelson. "The privatization process in Collor de Mello's Brazil: what went wrong!". Journal of Political Studies. 37, julio-diciembre, 2003: 35-57.

Green, Frederick (Coord.). A picture of wage inequality and the allocation of labor through a period of trade liberalization: the case of Brazil. Washington DC. The World Bank Group. 2004: 1923-1939.
Gremaud, Armaury Patrick; Sandoval, Marco A. y Toneto, Rudinei. Economia Brasileira Contempoânea. Rio de Janeiro: Editorial Atlas, 2005.

Maia, Kalia. "Progresso tecnológico, qualificação da mão-de-obra e desemprego". [Tesis de doctorado, Departamento de Economia].Universidade de Brasília, 2005: 452-461.

Moreira de la Hoz, Antonio. "La economía del gobierno de Lula: cambio o continuidad?". Santander, Universidad de Cantabria. 2006: 48-50. Mimeo.

Ocampo, José Antonio (coord). Una década de luces y sombras: América Latina y el Caribe en los años noventa. Bogotá: Comisión Económica para América Latina y el Caribe (CEPAL)/Alfaomega, 2001.

OECD. Brazil's economic statistics. Paris: OECD, 2000: 86-92.

Palermo, Víctor. Política brasileña contemporánea. De Collor a Lula en años de transformación. Buenos Aires. ITDT-Siglo XXI, 2006: 24-36.

Petriccioli, Jorge. Historia de las relaciones entre Brasil y Argentina. Quilmas. Universidad de Quilmes, 2006: 46-110.

Sforzi, Carlo. "The politic and the politics of Brazil and Argentina in the nineties". Rivista di Studi Sociali di Calabria 12. 2, junio, 2003: 41-57.

Tartakowski, Gonzalo y Chirulnicoff, Elena. Compendio estadístico del MERCOSUR. Montevideo. Oficina Central de Publicaciones del MERCOSUR, 2006: 561-603. 